\title{
A DÉCADA DE PROGRESSO EDUCATIVO PERDIDA SOB A NCLB: QUE LIÇÕES TIRAR DESSE FRACASSO POLÍTICO?*
}

\author{
LISA GUISBOND ${ }^{* *}$ \\ MONTY NEILL ${ }^{* * *}$ \\ BoB SCHAEFFER ${ }^{* * * *}$
}

\begin{abstract}
RESUMO: Dez anos se passaram desde que o presidente George W. Bush assinou a lei No Child Left Behind (NCLB). Uma revisão de uma década de evidências demonstra que a NCLB falhou tanto em termos de seus próprios objetivos como de forma mais ampla. Na verdade, por causa de sua dependência equivocada dos testes padronizados e sanções para as escolas, tem prejudicado muito os esforços pela reforma da educação. Muitas escolas, particularmente aquelas servindo alunos de baixa renda, se tornaram pouco mais que programas de preparação para testes. É hora de reconhecer essa falha e adotar um curso mais eficaz para o papel do governo federal na educação. Os formuladores de políticas devem abandonar estratégias baseadas na fé em testar e punir. Os dados acumulados ao longo de dez anos apontam que: 1) a NCLB afetou severamente a qualidade do ensino e a sua equidade; 2) a NCLB não conseguiu aumentar significativamente o desempenho acadêmico médio ou estreitar significativamente as diferenças de desempenho.

Palavras-chave: NCLB. Política pública. Equidade. Qualidade de ensino. Testes padronizados.
\end{abstract}

\section{NCLB'S LOST DECADE FOR EDUCATIONAL PROGRESS:} WHAT CAN WE LEARN FROM THIS POLICY FAILURE?

ABSTRACT: It has been ten years since President George W. Bush signed the law "No Child Left Behind" (NCLB). The revision of one decade of evidences demonstrates NCLB failures both in its objectives and in a broader way. In fact, its misguided dependence on standardized tests and sanctions applied to schools have been harming the efforts towards the educational reform. Many schools, particularly the ones attended by low income students,

\footnotetext{
* Tradução de Alain François, com revisão de Carolina Violante Peres.

* Coordenadora de Divulgação do Massachusetts Institute of Technology (MIT) e analista de Política do National Center for Fair \& Open Testing (FairTest). E-mail: lisa.guisbond@verizon.net

*** Doutor em Educação e diretor executivo do National Center for Fair \& Open Testing (FairTest). E-mail: monty@fairtest.org.

**** Tesoureiro e membro do Conselho de Administração do National Center for Fair \& Open Testing (FairTest).E-mail: bobschaeffer@earthlink.net
} 
became a little bit more than a test preparation program. It is about time to recognize this failure and to adopt a more effective course for de federal government's role in education. The policies developers should abandon strategies based on the faith in testing and punishing. The data accumulated in the last ten years point out that: 1) NCLB severally affected the quality of teaching and its equality. 2) NCLB was not able to significantly increase the average academic performance or to significantly narrow the performance gaps.

Key words: NCLB. Public policies. Equality. Teaching quality. Standardized tests.

\section{LA DÉCENNIE DE PROGRES EDUCATIF PERDUE SOUS LA NCLB: QUELLES LEÇONS TIRER DE CET ECHEC POLITIQUE?}

RÉSUMÉ: Dix années sont passées depuis que le président George W. Bush a signé la loi No Child Left Behind (NCLB). Une analyse d'une décennie d'évidences démontre que NCLB a failli tant en termes de ses propres objectifs comme de manière plus large. En vérité, à cause de sa dépendance erronée à des tests standardisés et à des sanctions envers les écoles, il a énormément porté préjudice aux efforts pour la réforme de l'éducation. Beaucoup d'écoles, particulièrement celles desservant les élèves de bas revenus, sont devenus progressivement plus que des programmes de préparation pour tests. Il est temps de reconnaître cette défaillance et d'adopter un chemin plus efficace pour le rôle du gouvernement fédéral dans l'éducation. Les formulateurs de politiques doivent abandonner les stratégies fondées sur la foi dans les tests et les punitions. Les données accumulées au long des dix années indiquent que: 1) la NCLB a affecté sévèrement la qualité de l'enseignement et de son équité; 2) la NCLB n’a réussi ni à augmenter significativement le niveau scolaire moyen ni même à en réduire significativement les brêches.

Mots-clés: NCLB. Politique publique. Equité. Qualité de l'enseignement. Tests standardisés.

$\mathrm{P}$

assaram-se dez anos desde que o presidente George W. Bush assinou a lei No Child Left Behind (NCLB - "Nenhuma criança deixada para trás"), que passou a reger a educação dos EUA. Basta rever as provas que se acumularam no período para afirmar que foi um fracasso retumbante tanto em termos dos objetivos almejados, quanto em termos gerais: não houve aumento significativo das performances acadêmicas ou redução expressiva das diferenças de desempenho, nem mesmo segundo os resultados de provas padronizadas.

De fato, por causa da sua confiança infundada num formato único de testes, rótulos e sanções para todas as escolas, ela solapou vários esforços em termos de reforma educacional. Muitos estabelecimentos, em particular os que atendem alunos de baixa renda, transformaram-se em pouco mais do que programas preparatórios para testes.

Está na hora de admitir esse fracasso e de conferir um rumo mais eficiente ao papel do governo na educação. Os decisores públicos devem abandonar as suas 
convicções baseadas na fé em estratégias de tipo testar e punir e adotar alternativas que, comprovadamente, podem guiar e apoiar as escolas e os alunos mais necessitados da nação. Os dados reunidos nesses dez últimos anos deixam três coisas claras:

1) A NCLB tem prejudicado seriamente a qualidade e a equidade da educação, com efeitos de estreitamento e limitação que afligem os pobres de modo mais implacável.

2) A NCLB fracassou significativamente em aumentar a performance acadêmica média ou em diminuir expressivamente as diferenças de desempenho.

3) As chamadas "reformas" da lei, como as isenções do governo Obama e a revalidação, pela Comissão de Educação do Senado, da Elementary and Secondary Education Act (Esea - Lei do ensino fundamental e médio), não afetam muitos dos erros fundamentais da NCLB e, em certos casos, agravaram-nos, pois vão dar continuidade a uma "década perdida para as escolas estadunidenses".

Apesar das provas contundentes juntadas nesses dez anos, que documentam o fracasso da NCLB e dos esquemas semelhantes de testes de alto impacto (high-stake tests), e a despeito dos indícios crescentes, nos EUA e no mundo, que mostram como melhorar as escolas, os decisores públicos agarram-se a modelos desacreditados. Isto é particularmente trágico para as famílias cujos filhos esperavam que a longa espera por oportunidades educativas iguais estivesse chegando ao fim. Também é dramático para o sistema público de educação dos EUA, cuja reputação foi maculada por promessas não cumpridas e esquemas de intervenção caros, que estragam mais do que melhoram.

Não é tarde demais para revisitar os dez últimos anos e elaborar uma lei federal que promova a equidade e o progresso em todas as escolas públicas. Com esse objetivo em mente, este relatório oferece, primeiro, um panorama das provas contra a NCLB. A seguir, examina os recentes esforços para "reformar" a NCLB e o que indícios passados dizem a respeito dos seus prováveis resultados. Finalmente, aponta para estratégias alternativas que podem alicerçar a revalidação de uma lei federal que melhoraria todas as escolas, e mais particularmente as que atendem os alunos mais necessitados.

\section{Parte I - O histórico: as promessas não cumpridas da NCLB}

O relatório de 10 anos de NCLB não dá motivos para muitas comemorações, quer julguemos a lei estritamente nos seus próprios termos, quer olhemos os seus impactos mais profundos. 
- Os próprios indicadores de progresso da NCLB revelam as principais falhas: o crescimento medido pelo National Assessment of Educational Progress (Naep - Avaliação Nacional do Progresso Educacional) estacionou, as diferenças de desempenho continuam iguais e as predições de "fracasso" escolar generalizado estão se confirmando.

- O currículo estreitou-se, a preparação para testes substituiu a escolaridade mais ampla, a trapaça desenfreou-se, a ajuda para as escolas necessitadas é mais do que insuficiente, e a NCLB contribuiu para o crescimento de uma perniciosa via direta da escola para a prisão.

- O foco estreito na responsabilização punitiva e nos testes levou os decisores públicos a ignorarem as consequências educativas reais da pobreza infantil, a qual cresceu de modo expressivo esses últimos anos.

\section{0 crescimento estagnou, as diferenças continuam}

Em vez de fazer com que as escolas tenham condições de oferecer um currículo rico e equilibrado e atendam as necessidades dos alunos individualmente, a lei as obrigou a restringir o currículo, a ensinar para testes e a lançar mão de métodos enganosos e antiéticos para melhorar as notas nas avaliações. E isto porque definiu a aprendizagem dos alunos e a qualidade das escolas nos termos estritos dos resultados em provas padronizadas. ${ }^{1}$

Os principais parâmetros da NCLB para medir os resultados são testes estaduais padronizados em matemática e leitura, aplicados anualmente da terceira a oitava série e uma vez durante o ensino médio. Quando a lei determinou que os exames da Naep servissem de medida independente, os dirigentes escolares e os professores temeram, com toda a razão, que fracassos em alcançar as metas nas avaliações resultassem em sanções para as suas escolas. Com tanto peso nos resultados, muitos estabelecimentos passaram a preparar os alunos para essas provas, ignorando outros aspectos da educação.

Obviamente, os resultados nas provas estaduais melhoraram mais do que os da Naep, que tenderam a estacionar. Contudo, à medida que os testes de performan$c e$ foram aumentando as exigências para uma meta de $100 \%$ de proficiência, mais escolas, em quase todos os estados, ficaram cada vez mais aquém. Isto se deve, em grande parte, à exigência legal de que cada um dos múltiplos grupos - raça/etnicidade, baixa renda, principiantes em língua inglesa e deficientes - tenha de mostrar um "Adequate Yearly Progress" (AYP - "Rendimento anual adequado"). No ano letivo de 2010-2011, 48\% das 100 mil escolas da nação não conseguiram alcançar os padrões do AYP. 
Já em termos de acompanhamento, embora tenha sido particularmente criticada pela sua definição errada de "proficiência", a Naep pode servir de medida independente para rastear se e quando melhoras ocorrem. De fato, por ser um teste padronizado baseado essencialmente em perguntas de múltipla escolha (apenas algumas exigem respostas curtas), é tecnicamente válido para gerar uma grade de resultados coerentes ano a ano.

Ora, os últimos resultados da Naep (NCES, 2011a, 2011b) confirmam as tendências detectadas na década passada (FairTest, 2009). No geral, o crescimento era mais rápido antes de a NCLB entrar em vigor. Os resultados das quartas séries em matemática, por exemplo, subiram 11 pontos entre 1996 e 2003, mas aumentaram apenas 6 pontos entre 2003 e 2011. Os de leitura mal se modificaram depois da NCLB. Nas quartas séries, aumentaram em apenas 3 pontos, para 221, entre 2003 e 2011, e têm permanecido nesse patamar desde 2007. Nas oitavas séries, a leitura aumentou parcamente em 2 pontos, passando de 263 a 265, nesse mesmo período. Desde o começo da NCLB, os rendimentos têm estagnado ou diminuído em quase todos os grupos demográficos, nas duas disciplinas e nas duas séries.

\section{Figura 1}

Tendências nos resultados médios em matemática das quarta e oitava séries

Figure A. Trend in fourth - and eighth - grade Naep mathematics average scores
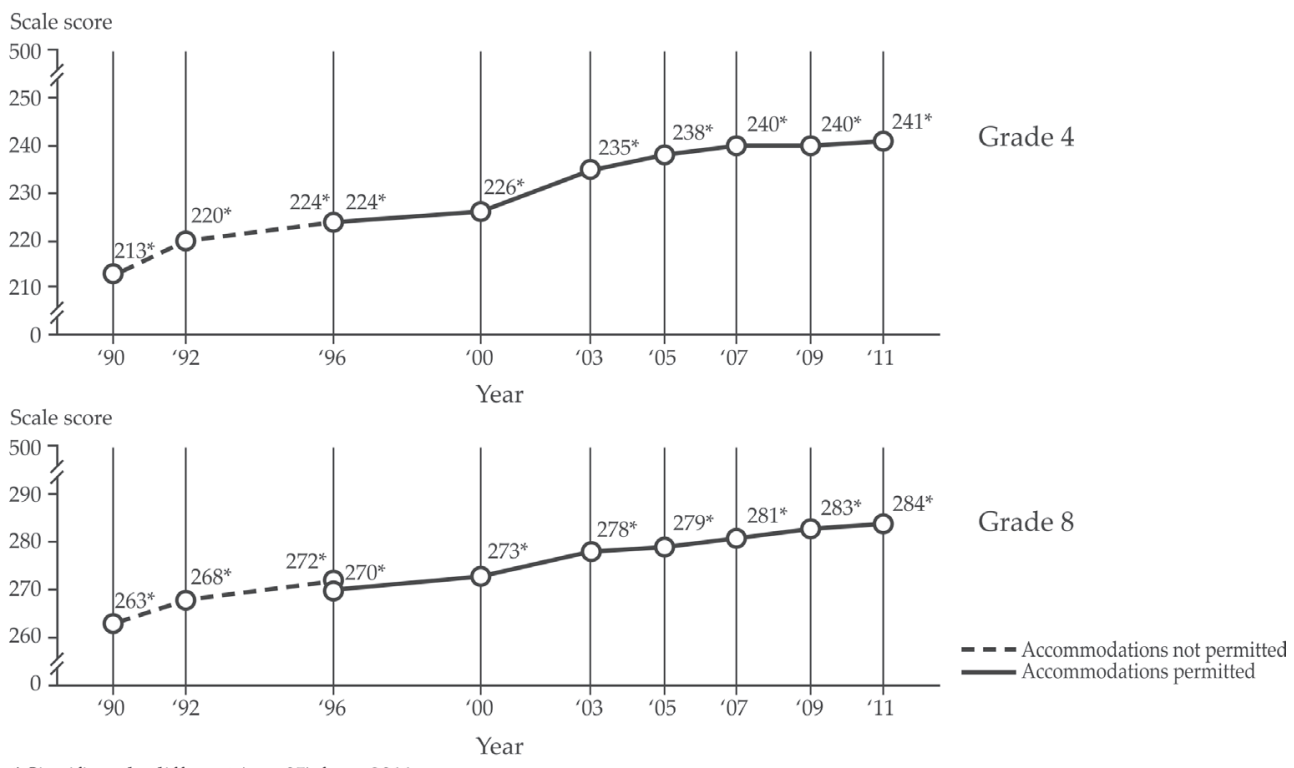

* Significantly different $(\mathrm{p}<.05)$ from 2011.

Fonte: NCES (2011a). 
Consequentemente, as diferenças entre grupos continuam grandes, apesar das expectativas de que, ao expô-las, a NCLB motivaria esforços bem-sucedidos para superá-las. Na realidade, estagnaram para a maioria dos grupos de alunos das duas séries, em ambas as disciplinas. Por exemplo, em matemática, nas oitavas séries, a grande diferença entre brancos e negros continuou em 32 pontos entre 2007 e 2009, e diminuiu apenas um ponto em 2011. Na leitura dos alunos das oitavas séries, o Wisconsin é o único estado que reduziu a diferença entre brancos e negros, entre 1998 e 2011, e apenas dois estados - Alabama e Califórnia - diminuíram a que separa brancos de hispânicos.

Aaron Pallas (2011), professor de Sociologia e Educação da Universidade de Columbia, estudou as mudanças de performance dos alunos brancos, negros e hispânicos em cada estado, nas quartas e oitavas séries, entre 2003 e 2011. Concluiu que a Naep

(...) não apresenta quaisquer provas de que os estados possam alcançar a meta laudável de fazer convergir o desempenho dos subgrupos de alunos para um nível de proficiência acadêmica significativamente mais alto do que é o caso atualmente. nenhum estado, nos últimos oito anos, conseguiu fazer isto do modo como a NCLB determina. (Pallas, 2011)

De fato, as tendências de longo prazo da Naep mostram apenas um período em que as diferenças de desempenho diminuíram drasticamente. Essa época de forte progresso rumo à equidade educacional se deu antes não apenas da NCLB, como também da maioria das políticas de testes de alto impacto.

\section{Figura 2}

Tendências nos resultados médios de brancos e negros em leitura e diferença de escore dos alunos de 17 anos

Trend in White - Black Naep reading average scores and score gaps for 17-year-old students

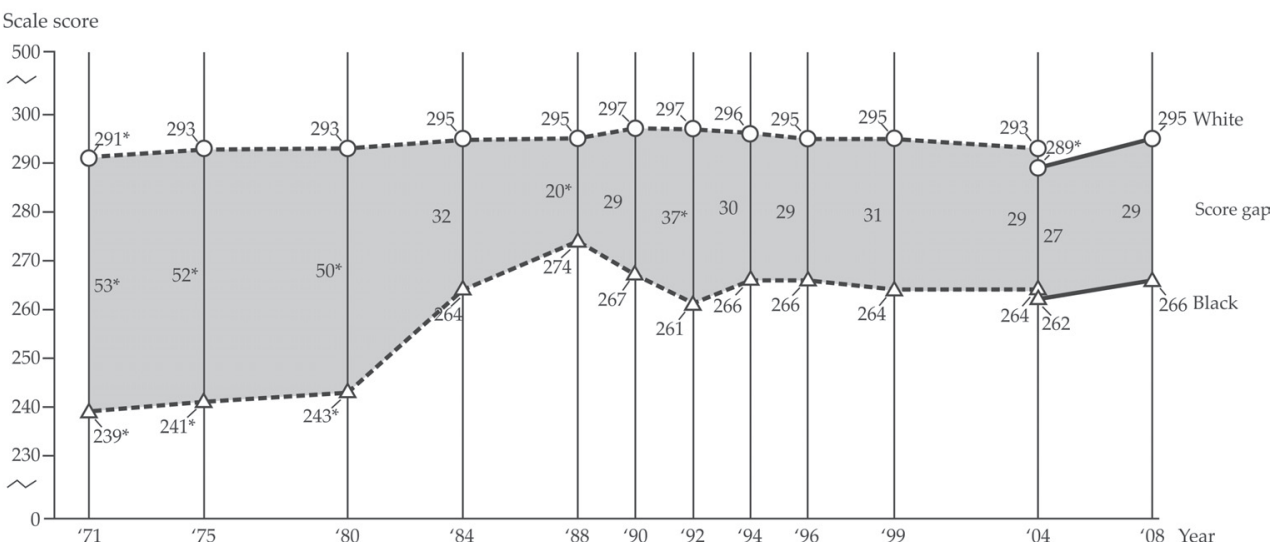

Fonte: NCES (2008). 


\section{Em sala de aula: excesso de testes, estreitamento do currículo, ensino focado nos testes, fraudes e outras formas de corrupção}

A NLCB passou a exigir resultados na forma de dados de exames, mas os resultados finais deixaram muito a desejar. Em consequência, a lei conseguiu transformar muitas escolas em âmbitos altamente focados, orientados por "dados". Os testes e as preparações para as provas proliferaram - o tempo dedicado a testes duplicou em algumas escolas. Um estudo do Government Accountability Office (GAO - Escritório de Prestação de Contas do Governo) para o Congresso estimou que os estados deveriam criar mais de 433 testes (a um custo oscilando entre 1,9 bilhões de dólares e 5,3 bilhões entre 2002 e 2008) para atender as exigências da NCLB (GAO, 2003). Isto é apenas a ponta do iceberg de um aumento maciço dos testes. Não raro, 20 a 60 dias letivos por ano são dedicados ao preparo de provas, sem falar dos dias de testes em si, que são muitos. No Massachusetts, por exemplo, haverá 33 sessões de teste estaduais em todas as séries, neste ano (Dese, 2011). Enquanto os benefícios dessa transformação são escassos, os custos educacionais são extremamente elevados.

Um deles é a interrupção do tempo de instrução para os alunos que mais precisam. A Wisconsin Association for Supervision and Curriculum Development (Associação para a Supervisão e o Desenvolvimento do Currículo do Wisconsin) tentou quantificar o tempo de aprendizagem que os alunos com necessidades especiais perdem por causa dos testes em geral. Descobriu que os professores passam em média 976 horas por distrito aplicando testes, o que é particularmente nocivo para esse tipo de estudantes:

\footnotetext{
Algumas escolas relataram que as populações de alunos desfavorecidos perdem até 15 dias - três semanas - de aulas educativas porque os especialistas estavam envolvidos na aplicação de testes. Nos doze anos que um aluno passa num distrito escolar, a interrupção do atendimento para alunos desfavorecidos, que apresentam mais riscos de não alcançar os objetivos da NCLB, pode chegar a até 36 semanas, ou seja, um ano inteiro. (Zellmer et al., 2006)
}

Às vezes, é preciso um verdadeiro escândalo para que as perdas de aprendizagem devidas à NCLB venham à tona. Na Field Elementary School de Dallas, no Texas, os alunos receberam notas em disciplinas que não lhes foram ensinadas para esconder que a escola enfocava exclusivamente as matérias testadas pela NCLB. O estabelecimento tirou uma nota "exemplar" no estado, mas os alunos receberam uma educação cheia de falhas. Um relatório do Office of Professional Responsibility (OPR - Escritório de Responsabilidade Profissional) do distrito escolar independente de Dallas cita o testemunho de professores da escola, que foram instruídos pelo diretor a deixar de lado as aulas de música, artes, e ciências. Num e-mail explicando por que um professor de matemática/ciências deveria se focalizar na matemática, o 
diretor escreveu: “Como as crianças são muito fracas em matemática, [o professor] deve investir nessa matéria (...). Este é um ano crucial e não podemos nos dar ao luxo de ver as notas Taks (Texas Assessment of Knowledge and Skills - Avaliação do Conhecimento e das Competências do estado do Texas) dos alunos caírem para 3 [nota mais baixa]" (OPR, 2011). Professores testemunharam que discordaram dessas diretivas, mas sentiram que perderiam os seus empregos se não obedecessem.

Além do mais, uma epidemia de fraude passou a assolar a nação inteira. Em Atlanta, onde logros envolvendo 178 professores e diretores foram comprovados em 44 escolas públicas, um relatório da Georgia Bureau of Investigation (GBI - Agência de Investigações da Georgia) descreveu uma cultura de "medo, intimidação e retaliação espalhada pelo distrito afora" (GBI, 2011). No fim de 2011, investigadores da Georgia publicaram outro relatório que documentava trapaças generalizadas nos testes em Dougherty Country, $320 \mathrm{~km}$ ao Sul de Atlanta. Encontraram provas de fraudes em cada uma das onze escolas do condado e de que professores foram coagidos a corrigir as respostas erradas dos alunos. Entre as três principais causas citadas, a primeira era: "a pressão para conseguir um rendimento anual adequado segundo a Lei do No Child Left Behind (Nenhuma criança deixada para trás)".

Essas histórias de corrupção e fraudes na era da NCLB são tão comuns que não podem ser creditadas a uns poucos indivíduos. Antes, são um resultado previsível e inevitável da pressão para alcançar as metas dos resultados nos testes, independentemente das circunstâncias. Segundo os relatórios publicados nesses últimos três anos, logros foram confirmados em 30 estados e no District of Columbia (Distrito Federal), cuja ex-superintendente, Michelle Rhee, fez uma campanha nacional para "melhorar os resultados".

Essa epidemia de trapaças e outras formas de corrupção é um exemplo clássico da lei de Campbell (1976, p. 49), que afirma: “Quanto mais um indicador social quantitativo é usado para tomar decisões sociais, mais estará sujeito a pressões de corrupção e fadado a distorcer e corromper os próprios processos sociais que deveria monitorar".

O National Research Council (NRC - Conselho Nacional de Pesquisa) da National Academy of Sciences (Academia Nacional de Ciências) estudou as provas acumuladas sobre as políticas baseadas em testes, inclusive a lei federal do No Child Left Behind, os testes de graduação estaduais e as políticas que dão gratificações aos professores cujos alunos obtêm notas melhores (Hout \& Elliott, 2011). O relatório concluiu que os incentivos baseados em testes como os da NCLB aumentam o ensino focado nos exames e produzem um retrato inflado e incorreto do que os alunos sabem. Também mostrou que os docentes sujeitos a sanções tendem a se focalizar nas medidas que melhoram os resultados nos testes, como ensinar estratégias para 
se dar bem nas provas ou dar mais atenção aos alunos nos limites da proficiência, em vez de melhorar a aprendizagem.

Várias fontes (como, por exemplo, Au, 2007; McMurrer, 2007; Nasbe, 2003; NCES, 2007) citam provas abundantes dos efeitos de estreitamento da NCLB. Em dezembro de 2011, Common Core (Tronco Comum, 2011) publicou os resultados preliminares de uma pesquisa por questionário aos professores: $66 \%$ disseram que o foco da NCLB na matemática e na leitura tem reduzido significativamente o tempo dedicado à arte, às ciências e aos estudos sociais. Outros relatórios mostram que muitas escolas estão diminuindo o recreio para aumentar o tempo dedicado a preparar testes, mesmo com crianças mais novas.

“Na última década, para atender à lei do No Child Left Behind, nossas escolas públicas têm se dedicado - quase exclusivamente - ao ensino de leitura e matemática", disse Lynn Munson, presidente e diretora executiva de Common Core. Embora a NCLB "defina claramente o 'currículo de base' como sendo leitura, matemática, ciências, estudos sociais, e mesmo artes", muitas matérias foram "abandonadas", explicou. "Consequentemente, estamos negando aos nossos alunos a educação completa que merecem e que a lei exige" (Common Core, 2011).

$\mathrm{O}$ mais inquietante é que a lei exacerbou as desigualdades com as quais pretendia acabar. Um relatório do Council for Basic Education (Conselho de Educação Básica - Von Zastrow \& Janc, 2004) encontrou provas de que o estreitamento é pior ainda nas escolas com mais alunos de baixa renda ou oriundos de minorias.

No seu livro Tested: one American school struggles to make the grade (Testada: uma escola americana luta para estar à altura - 2007), resultado do ano que passou na Tyler Elementary, uma escola para alunos de baixa renda do distrito escolar do condado de Anne Arundel (Maryland), Linda Perlstein explicou como funciona:

O fato de filhos de famílias abastadas e pobres terem experiências escolares diferentes não é nada novo. O mais significativo é que as disparidades continuem, apesar de (e, de algum modo, por causa de) um movimento planejado para acabar com elas. A prática de se focalizar nas matérias testadas, leitura e matemática, em detrimento de um currículo equilibrado, está prevalecendo onde as crianças são pobres e pertencem a minorias. "Quem não sabe ler nunca vai ser cientista", disse-me uma vez um diretor para defender o currículo reduzido da escola. bem, ninguém vai ser cientista - um dos objetivos profissionais mais citados pelos formandos de quinta série da Tyler Heights - se nunca aprender ciências (...). (2007, p. 135)

\section{o papel da NCLB no afastamento de alunos e a crescente via direta da escola para a prisão}

O afastamento de alunos com notas baixas nos testes para melhorar o resultado final de uma escola é tão nocivo quanto os efeitos de estreitamento e de 
banalização da NCLB. Sharon Nichols e David Berliner compilaram provas substanciais de que isso ocorre, no seu livro Collateral damage (Danos colaterais, 2007), inclusive em Birmingham, Alabama, onde 500 alunos foram afastados do ensino médio antes da época dos testes, e na cidade de Nova Iorque, onde um processo judiciário expôs políticas que incitaram milhares de alunos com notas baixas a largar a escola. Essas práticas, que afetam essencialmente alunos de cor (students of color) ou com deficiências, estão vinculadas ao crescimento rápido de uma "via direta da escola para a prisão", que está levando cada vez mais estudantes perante o sistema de justiça criminal. Certamente, esse crescimento não tem uma causa única, mas, em 2011, um documento com a posição de vários grupos de direitos civis e de educação explicava o papel desempenhado pela exigência federal de testes:

\begin{abstract}
A NCLB surtiu o efeito de estimular as escolas com performance baixa a atingir os critérios, estreitando o currículo e a instrução e tirando a prioridade das oportunidades educativas de muitos alunos. Obviamente, a abordagem "linha dura" das responsabilidades, na No Child Left Behind, fez com que um maior número de alunos fosse deixado mais atrás ainda, alimentando assim a crise do abandono escolar e a via direta da escola para a prisão. (Advancement Project et al., 2011, p. 1)
\end{abstract}

\title{
Muita responsabilização e pouco apoio para melhoras
}

Algumas das falhas da NCLB poderiam ser perdoadas se tivessem levado a melhoras sustentáveis para muitos alunos e escolas necessitados. Em vez disso, a lei, com uma abordagem errada das responsabilidades, deitou alicerces para um tratamento igualmente errado das ofertas de opções para os pais ou para a melhoria das escolas. Uma peça chave foi a disposição que autorizava os pais a transferirem os filhos de escolas que não alcançassem o AYP (Adequate Yearly Progress - Rendimento Anual Adequado) para outras do mesmo distrito que o atingissem. Um relatório GAO de dezembro de 2004 mostrou que menos de 1\% dos alunos, podendo ser transferidos segundo a lei, o fez no ano letivo 2003-2004. Um segundo remédio da NCLB, a prestação de serviços educacionais suplementares, tem canalizado o dinheiro para empresas privadas de aulas particulares sem o menor efeito positivo mensurável para os alunos. NCLB's supplemental educational services: is this what our students need? "Os serviços educacionais suplementares da NCLB: é disto que os nossos alunos precisam?") relata que apenas 233 mil, ou seja, 11\% dos dois milhões de alunos elegíveis no país inteiro, tiraram proveito dos serviços educacionais suplementares da NCLB, geralmente de baixa qualidade, pois se limitam a estender "a agenda educativa reduzida" da NCLB "a alunos em horários extraescolares" (Ascher, 2011, p. 136). 
A NCLB não investiu na construção de novas escolas em distritos desfavorecidos, nem fez os distritos ricos, com melhor performance acadêmica, abrirem suas portas a alunos de distritos pobres. Antes, criou um cardápio de opções de reestruturação para as escolas que não conseguissem ter um rendimento anual adequado por seis anos consecutivos. As possibilidades são as seguintes: ser estatizada; entregar a gestão a empresas privadas; fechar e reabrir como charter school'; ou reconstituir a escola substituindo alguns ou todos os membros da administração, dos funcionários ou dos docentes. Uma quinta opção prevê "qualquer outra reestruturação de peso na governança da escola".

Numa síntese de 2009, o pesquisador William J. Mathis estudou o histórico desse tipo de intervenções. No geral, constatou que não havia muitos registros de que qualquer uma dessas abordagens tenha sido usada para reestruturar escolas com dificuldades e que, quando foi o caso, havia poucos indícios de sucesso. As charter schools, por exemplo, foram raramente escolhidas como opção de reestruturação, e, seja como for, nos fatos, "em se tratando de fatores demográficos, as charter schools não apresentam vantagens".

Mathis (2009, p. 17) concluiu: “Uma vez que essas abordagens são propostas para as escolas mais problemáticas da nação, é provável que as soluções [atualmente propostas pela NCLB] sejam deploravelmente insuficientes". Além do mais, os estados não têm condição de implementar esses remédios drásticos de reestruturação. Embora alguns defensores da NCLB pensassem que a lei os forçaria a realocar verbas ou a captar novos recursos para amparar as escolas de baixa renda com resultados fracos, não tem sido o caso. Muitos estabelecimentos continuam tendo sérios problemas de subsídios e existem fortes desigualdades de financiamento tanto dentro de um dado distrito, quanto entre os distritos de um mesmo estado (FEA, 2011).

\section{0 foco nos testes evita ter de enfrentar as consequências da pobreza infantil}

Uma das razões pelas quais a NCLB estava fadada a não atingir as suas metas elevadas tem pouco a ver com as suas providências ou implementação errôneas. Bem no meio do caminho rumo a " $100 \%$ de proficiência" surgiu a pior crise econômica desde a Grande Depressão. Segundo um relatório recente do U.S. Census Bureau (Departamento do Censo dos EUA, 2011), a pobreza infantil subiu para 22\%, e 96 dos 100 maiores distritos escolares reportaram um crescimento do número de crianças pobres. Enquanto isso, tantos os recursos escolares quanto o suporte social de que as crianças precisam para aprender e ter sucesso na escola (moradia, estabilidade familiar e comunitária, cuidados médicos e dentários) sofreram cortes. Assim, as escolas devem educar cada vez mais crianças para as quais os alicerces do êxito escolar estão desmoronando. 
Exigir resultados iguais numa sociedade desigual seria uma ilusão perigosa, mesmo sem a crise fiscal. Esperar que as escolas contenham o amplo impacto da pobreza infantil, e não apenas evitem que essas crianças fiquem mais atrás ainda, mas também acelerem o seu crescimento acadêmico para reduzir as diferenças em termos de desempenho, como quer a NCLB, significa passar por cima de pilhas de provas que mostram como a pobreza afeta a capacidade de aprendizagem das crianças, a começar pelo histórico relatório Coleman (1966). Este não havia como prever o assombroso crescimento da desigualdade de renda e da pobreza infantil dessas últimas décadas. Contudo, quem elaborou as prescrições políticas durante a última década deveria ter levado em conta as diferentes maneiras como a pobreza afeta a capacidade de aprendizagem de uma criança (Rothstein, 2004; Berliner, 2009).

O livro Whither opportunity? ("Oportunidade, onde?"), organizado pelos professores Greg Duncan e Richard Murnane (2011), documenta essas desigualdades crescentes em termos de renda e educação e os modos como estão vinculadas. Num artigo de fundo (op-ed) onde exprimem publicamente a sua opinião, no Chicago Tribune (6 de outubro de 2011), Duncan e Murnane explicam:

As desigualdades econômicas crescentes multiplicaram os modos de ampliar o abismo entre os resultados educacionais das crianças ricas e pobres. No começo dos anos de 1970, a diferença entre o que os pais dos quintis superior e inferior gastavam em atividades enriquecedoras, como aulas de música, viagens e acampamentos de verão, era de aproximadamente 2.700 dólares por ano (em dólares de 2008). Em 2005-2006, aumentou para 7.500 dólares. De 0 a 6 anos, os filhos de famílias com rendimentos mais elevados passam uma média de 1.300 horas a mais do que os de famílias de baixa renda em lugares "novos" - outros que não a sua casa ou a escola -, ou sendo cuidados por outro parente ou numa creche. Isto importa, pois quando pedimos que as crianças leiam textos de ciências e de estudos sociais nas últimas séries do primário, o conhecimento prévio é crucial para a compreensão e o êxito escolar.

Aqueles que chamam a atenção para a influência da pobreza sobre os resultados educativos são acusados de fornecer desculpas para o fracasso das escolas em apagar as diferenças de desempenho. Os defensores do "sem desculpas" acusam-nos de dizer que as crianças pobres não podem aprender.

Essa denúncia é uma manobra de diversão. Muito pode e deve ser feito para melhorar as escolas. Contudo, a NCLB deixou de considerar as consequências da pobreza e foi uma desculpa para não enfrentá-las. Obviamente, como era de se prever, as "reformas" educacionais propostas pela lei têm fracassado em melhorar as escolas ou a aprendizagem (Neill, Guisbond \& Schaeffer, 2004).

Nesse décimo aniversário, existem muitas provas de que as premissas errôneas da NCLB - que testes de alto impacto aliados a sanções melhorariam os resultados sem ter de enfocar outras questões educacionais ou as da pobreza - causaram 
o fracasso da lei. Claramente, já passou da hora de instaurar uma mudança importante. O problema é que a maioria das propostas na mesa muda mais a retórica do que a substância.

\section{Parte II: Vinho avinagrado com novos rótulos}

Não há dúvidas de que o secretário Duncan ouviu um coro de queixas contra os efeitos nocivos da NCLB - de inspetores de educação, diretores, professores, pais, alunos, ativistas comunitários e pesquisadores. Consequentemente, costuma-se falar em testes errados ou limitados e currículos estreitados, fazendo eco a essas queixas insistentes. Contudo, as suas propostas e iniciativas dão sequencia a maioria dos piores aspectos da NCLB e acrescentam outros, igualmente não fundamentados e prejudiciais.

- Nem as isenções do governo, nem o projeto de lei da Comissão Help (Health, Education, Labor and Pensions - Saúde, Educação, Trabalho e Aposentadorias) do Senado propõem reduzir o uso excessivo e generalizado de testes padronizados que surgiu na esteira da NCLB.

- Essas duas propostas abandonariam as disposições destruidoras e irrealistas do AYP (Adequate Yearly Progress - Rendimento Anual Adequado), mas ambas mantêm ou mesmo ampliam muito do que não tem funcionado. O programa Race to the Top (RTTP - Corrida para o topo) de Duncan e as propostas de isenções, em particular, mostram o malogro do governo em levar em conta as provas que explicam por que a NCLB fracassou.

\section{0 papel dos testes cresce inexoravelmente}

Além das exigências básicas por testes, a NCLB gerou uma proliferação aparentemente infinita de testes e maneiras de usá-los: provas padronizadas em mais matérias, testes intercalares ou simulados (benchmark). Deu à luz os chamados testes "formativos", que, supostamente, ajudam a melhorar a instrução, mas, na realidade, diminuem o tempo que lhe é dedicado. A NCLB também alimentou o crescimento de uma indústria de testes altamente lucrativa, cujos proventos aumentaram enquanto o desempenho dos estudantes na Naep (National Assessment of Education Progress - Avaliação Nacional do Rendimento Escolar) se estabilizou e as diferenças de desempenho estagnaram. O secretário Duncan ouviu muitas chamadas para aliviar a avalanche de testes e, às vezes, pareceu disposto a atendê-las.

O Ministério da educação dos EUA, por exemplo, alegou que um dos motivos que levou ao programa de isenções era que: "a NCLB deu peso demais a um único 
teste padronizado aplicado num único dia. essa é a maior queixa dos professores contra a lei. sentem-se pressionados a preparar alunos para esse teste, levando a um estreitamento involuntário do currículo e a uma ênfase nas competências básicas medidas por testes padronizados" (U.S. DOE, 2011).

Segundo esse raciocínio, a resposta óbvia da administração seria a de aliviar essa pressão. num sentido, pareceu fazê-lo, quando suprimiu o odiado mecanismo de rendimento anual adequado, da NCLB. Contudo, o papel predominante dos testes continua firme e, provavelmente, vai se intensificar na maioria dos estados.

Com o plano de isenções, ${ }^{3}$ os estados devem continuar as avaliações anuais em leitura e matemática para todas as crianças da $3^{\underline{a}}$ a $8^{\underline{a}}$ série, e uma vez durante o ensino médio, mas com novos testes, baseados em college and career standards ("padrões de universidade e vida profissional"). Ao que tudo indica, os novos testes vão ser muito semelhantes aos atuais, só que mais difíceis. As isenções também exigem que os estados adotem medidas de "crescimento dos alunos", as quais passam a ser um "fator expressivo" na avaliação dos professores e diretores. Isto tem levado alguns estados a adotarem técnicas estatísticas, cuja imprecisão grosseira já foi comprovada por várias pesquisas. Pior ainda, intensificou-se o foco na melhora dos resultados nos testes em vez de garantir uma educação abrangente a todas as crianças. Em outras palavras, perpetuam a falsa noção de que se pode engordar um porco pesando-o com mais frequência.

O governo diz que, quando um estado não dispõe de testes para dadas matérias, precisará ter, quando não mais testes, "medidas permitindo comparações" para poder quantificar o "crescimento" dentro de um distrito. Isto poderia impelir os distritos a comprarem ou criarem dezenas de novas provas, com custos elevados e prováveis grandes danos para as disciplinas não testadas hoje em dia. A cidade de Charlotte-Mecklenburg (Carolina do Norte), por exemplo, alocou 1,9 milhões de dólares para criar 52 novos testes que avaliam os professores (Grundy \& Sawyer, 2011; The Herald Weekly, 2011).

O plano de isenções é particularmente perigoso porque a maioria dos estados (39 mais o Distrito de Columbia) não pediu e nem anunciou que vai pedir uma derrogação (McNeil, 2011). Além do mais, parece improvável que a Elementary and Secondary Education Act (Esea - Lei do Ensino Fundamental e Médio), hoje em dia chamada de NCLB, seja revalidada antes das eleições de 2012. Assim, o plano de isenções poderia moldar dramaticamente a escolaridade nos EUA e reforçar a predominância dos testes (Foley \& Neill, 2011).

Alguns estados, como a Califórnia, rejeitaram as isenções, por motivos que vão desde os seus efeitos potencialmente prejudiciais sobre a educação até os altos custos com que estados e comunidades teriam de arcar para implementá-las, 
enquanto a crise fiscal os força a cortarem seus orçamentos. É possível que, antes de submeterem as suas propostas de isenções, mais estados percebam que se trata de um mau negócio, e pressionem o secretário Duncan a derrogar as exigências do AYP sem a compensação, ou "presente de grego", de usar os resultados dos alunos nos testes para julgar os professores nem outros esquemas de isenções não garantidos. O projeto de lei Help do Senado também nunca vai reduzir o papel central dos testes na revalidação da Esea, pois: mantém todas as avaliações da NCLB; define funcionalmente "desempenho" como pontuação em testes; e usa estes últimos como base quase que única para muitas decisões educacionais (Foley \& Neill, 2011). Contudo, não é só assim que as chamadas reformas ignoram as provas existentes e ameaçam exacerbar o papel nocivo dos testes nas escolas.

\section{Uma nova ferramenta de alto impacto: vincular os resultados dos alunos nos testes às avaliações dos professores}

Embora vários estudos comprovem que vincular os resultados dos alunos nos testes às avaliações dos professores é injusto, impreciso e ainda longe de estar pronto para uso, o secretário Duncan decidiu levar essa exigência controvertida à frente da Race to the Top (RTTT) ${ }^{4}$ no Programa de isenções da NCLB. De novo, em vez de resolver os problemas amplamente reconhecidos do ensino para testes, que estreita o currículo e perpetua fraudes e outros tipos de corrupção, essa "inovação" vai exacerbá-los ao conferir aos resultados dos testes um impacto mais alto ainda para os professores.

Em novembro de 2011, a Education Writers Association (Organização Nacional de Jornalistas de Educação) publicou uma síntese sobre a avaliação dos professores baseada em mais de 40 estudos e entrevistas com especialistas (Sawchuk, 2011). A conclusão foi que as pesquisas existentes não apoiam vincular as avaliações dos professores aos resultados dos alunos nos testes, por vários motivos:

- Os professores não são o fator mais importante no desempenho dos estudantes, o qual é essencialmente um produto das características do histórico do indivíduo e da família.

- Os métodos com valor agregado para avaliar os professores, politicamente populares, não costumam ser confiáveis ou estáveis. Podem até ressaltar algumas diferenças de qualidade entre professores, mas sofrem a influência de vários fatores, inclusive os controles estatísticos e as características das escolas e dos outros alunos.

- Embora haja quem afirme que o desempenho dos alunos pode ser muito influenciado pelo fato de terem professores altamente eficientes por vários 
anos seguidos, a eficiência de um professor muda de ano a ano. O impacto de um professor eficiente parece diminuir com o tempo, de modo que os efeitos cumulativos de ter melhores professores por vários anos seguidos não são claros.

- Nos Estados Unidos, recompensar os professores cujos alunos melhoram (método às vezes chamado de "pagamento por mérito") não se traduziu em melhora no desempenho dos estudantes.

Jesse Rothstein (2010), economista da Universidade da Califórnia (Berkeley), ofereceu a mais sucinta avaliação dos métodos com valor agregado ao dizer que, para medir a qualidade dos professores, eles são "ligeiramente melhores do que jogar cara ou coroa".

Apesar das provas (ver também Neill, 2011), a pressão e os incentivos da RTTT e do programa de isenções da NCLB levaram os estados a seguirem em frente determinadamente no planejamento e na implementação de programas de avaliação dos professores vinculados aos resultados dos alunos nos testes. Pelo menos 23 estados e a Capital, Washington, avaliam-nos parcialmente pelos resultados nos testes, e 14 estados permitem que os distritos usem esses dados para demitir professores.

O Tennessee saiu na frente na competição da RTTT. Implementou agilmente um sistema em que metade da avaliação dos professores se baseia no "desempenho dos alunos" (35\% desta metade provêm de medidas de crescimento baseadas nos resultados dos estudantes nos testes estaduais), e ainda exige frequentes avaliações por parte do diretor. Ora, o sistema causou tanta frustração e confusão que o comissário estadual para a Educação, Kevin Huffman, logo exigiu modificações. Um dos problemas é que, em muitos estados, a maioria dos docentes ensina matérias não avaliadas, de modo que não existem resultados de testes para avaliá-los. O Tennessee "resolveu" esse problema ao autorizar que esses professores sejam avaliados em função dos resultados numa disciplina que não ensinam. Por exemplo, um professor de Educação Física poderia "escolher" ser avaliado em função dos resultados na escrita. Will Shelton, diretor da Blackman Midddle School, no Tennessee, descreveu o sistema assim: "Jamais vi tanto absurdo. Nos cinco anos em que tenho sido o diretor aqui, nunca soube tão pouco sobre o que estava ocorrendo no meu próprio estabelecimento" (Winerip, 2011).

Em Nova Iorque, um plano semelhante levou a uma explosão de resistência sem precedente. No fim de dezembro, quase $23 \%$ dos diretores de escola do estado de Nova Iorque (1.058) haviam assinado uma declaração de protesto, repudiando

(...) um sistema não comprovado que desperdiça cada vez mais recursos limitados. Mais importante ainda, será profundamente desmoralizador para os docentes e prejudicial para as crianças sob nossos cuidados. Nossos alunos são mais do que a soma dos seus 
resultados nos testes, e uma ênfase exagerada nesses resultados não vai redundar em melhor aprendizagem. (Diretores de NY, 2011)

\section{Apesar da falta de sucesso, as estratégias de remendo continuam na ordem do dia}

O Programa de isenções do governo e a lei Help do Senado eliminaram a AYP e, no seu lugar, criaram categorias muito mais limitadas de escolas precisando de intervenção. Os estados que receberam isenções devem centrar os esforços de recuperação em apenas $5 \%$ dos estabelecimentos, as assim chamadas escolas "prioritárias", que têm os piores resultados. Nos 10\% acima (as escolas em "foco"), as intervenções visam os grupos de alunos com performance mais baixa, e que poderiam se aproveitar das opções de transferência e monitoramento que não surtiram efeitos na NCLB. Do mesmo modo, o projeto de lei Help do Senado determina intervenções nos 5\% inferiores das escolas definidas com base nos resultados nos testes ou, para o ensino médio, nas taxas de formaturas.

Esse aceno para a capacidade limitada dos estados leva em conta uma pequena dose de realidade. Contudo, as alternativas para remendar o programa de isenções vinculam-se estreitamente à NCLB, pois incluem a reabertura como charter schools, a substituição da maioria ou da totalidade do pessoal, a entrega da governança a uma entidade externa, ou "qualquer outra reestruturação de peso".

As opções para as isenções incluem:

- Um modelo de recuperação que substituiria o diretor e não mais do que metade do pessoal.

- Um modelo de recomeço em que a escola seja reconvertida ou fechada e reaberta sob o controle de uma organização de gestão escolar, que poderia ser uma charter school.

- A escola poderia simplesmente ser fechada e seus alunos matriculados em outras escolas.

- Um modelo de transformação, "que modifique persistentemente as escolas com os piores desempenhos, levando em conta quatro áreas críticas: desenvolver a eficiência de liderança dos professores e diretores, implementar estratégias de reformas educacionais abrangentes, alongar o tempo de ensino e criar conexões comunitárias, e providenciar flexibilidade operacional e apoio sustentado".

Esse último modelo é uma versão mais leve das exigências da RTTT, mas, pelo menos, oferece a possibilidade de tomar medidas autênticas de melhoria. Entretanto, 
nenhum financiamento federal acompanha essas abordagens onerosas de aprimoramento das escolas.

As estratégias de remendo do projeto de lei Help do Senado, embora semelhantes, incluem três opções suplementares que poderiam permitir mais flexibilidade (Foley \& Neill, 2011). Além disso, o Help exige que os distritos empreendam ações específicas de melhora daqueles " $5 \%$ " de escolas, baseadas numa revisão da instituição e arraigadas em aspectos como desenvolvimento profissional e colaboração, que comprovaram acarretar verdadeiras melhoras em escolas quando bem feitas. Até certo ponto significativo, neste caso, a Comissão atendeu às recomendações das organizações de educação e outras (FEA, 2011b).

Por falta de provas, os oficiais governamentais recorrem a anedotas para realçar escolas "modelos" e mostrar que as suas prescrições têm funcionado no passado. Entretanto, Diane Ravitch, especialista em educação, examinou todos esses casos minuciosamente e não encontrou milagre algum (Ravitch, 2011b). Por exemplo, o Presidente viajou para a Florida em março para encontrar o governador Jeb Bush e elogiar as transformações na Miami Central High, após mais de metade do pessoal ter sido demitido. Ravitch mostrou que essa "escola milagrosa" continua tendo uma das performances mais baixas da Florida e que só não foi fechada por um triz.

Embora as recuperações milagrosas sejam raras, estratégias baseadas em soluções comprovadas melhoraram o desempenho escolar. A próxima seção deste relatório resume abordagens alternativas à reforma NCLB que incluem essas experiências da vida real.

\section{Parte III: Uma reforma real é possível, mas implicaria estabelecer um novo rumo baseado em evidências}

Os autores da NCLB tentaram dar à lei certo nível de seriedade ao preconizar que "pesquisas cientificamente fundamentadas" (Scientifically Based Research - SBR) deveriam guiar as práticas educativas. A lei define as SBR como "pesquisas que envolvem a aplicação de procedimentos rigorosos, sistemáticos e objetivos para obter conhecimentos confiáveis e válidos atinentes a atividades e programas educacionais". Desde o início, muitos argumentaram, inclusive o pessoal do FairTest (Neill, Guisbond \& Schaeffer, 2004), que as pesquisas existentes sobre testes de alto impacto, estratégias de remendo (turnaround) e outros aspectos da lei deveriam ter levado os autores da NCLB em direções muito diferentes. Infelizmente, esses apelos surtiram pouco efeito.

Por sorte, existem modelos de práticas bem-sucedidas, nos EUA e fora, que poderiam servir de base para revisar a Esea e apoiar reformas educacionais significativas e sustentáveis. 
Linda Darling-Hammond (2010), Diane Ravitch (2011a), Tony Wagner (2011) e muitos outros observaram que a Finlândia, que está sempre no topo das classificações internacionais, por exemplo, reformou drasticamente suas escolas durante 20 anos para alcançar um grau elevado de equidade e qualidade, com políticas diametralmente opostas às da NCLB. Não existem testes de alto impacto para classificar os alunos ou as escolas. Os professores não são avaliados com base nos resultados dos alunos em testes, nem demitidos em massa. As "escolas com dificuldades" não são fechadas. Nenhum perito intervém para remendar as coisas. Não há currículos roteirizados nem simulados frequentes para preparar para um grande teste.

Antes, a Finlândia preocupou-se em garantir recursos educacionais equitativos no país afora - e até mesmo em subsidiar mais as escolas que atendem os alunos mais necessitados. Desenvolveu tanto um corpo docente forte, sindicalizado, que trabalha junto para melhorar a escolaridade, quanto um currículo sólido e abrangente. O país investe pesadamente em formação e desenvolvimento de professores e, então, trata com grande autonomia e respeito esses profissionais bem preparados e apoiados. Outras nações com excelentes classificações, como Singapura e Hong Kong, seguem abordagens semelhantes, e os alunos colhem os frutos (Darling-Hammond, 2011).

É mais difícil achar modelos bem-sucedidos e abrangentes nos EUA, em parte por causa da sociedade profundamente desigual e, em parte, porque todas as escolas públicas são regidas pelas exigências inflexíveis da NCLB. Contudo, em menor escala, algumas escolas demonstram ter melhores métodos de avaliação, como o uso de múltiplas medidas da aprendizagem dos alunos (FairTest, 2010a). As escolas de ensino médio do New York Performance Standards Consortium (Consórcio de Padrões de Rendimento de Nova Iorque, s.d.), por exemplo, têm se aproveitado de uma discórdia no Board of Regents (Conselho dos Regentes) do estado para limitar os testes padronizados ao exame estadual de English Language Arts (ELA - Língua e Literatura Inglesa). Atendem às exigências de responsabilidade estaduais e federais ao usarem o teste de ELA junto com os seus próprios testes de matemática e literatura e outros baseados em avaliações da performance.

Com essa flexibilidade, essas escolas, cuja população escolar corresponde mais ou menos à das escolas públicas da cidade de Nova Iorque, conseguiram criar um sistema com expectativas e resultados extremamente elevados. Segundo o site do Consórcio (s.d.),

Os exames [de performance] exigem que os alunos demonstrem as suas capacidades em termos de pensamento analítico, leitura e compreensão, as suas competências escritas para a pesquisa, para cálculo e resolução de problemas, para tecnologia computacional, para o uso de métodos científicos para empreender pesquisas científicas, para a apreciação das artes e a sua execução, para a aprendizagem de serviços comunitários e da "escola para a vida profissional" (school to career). 
As taxas de abandono escolar são muito baixas (9,9\% contra 19,3\% para a cidade inteira) e as de ingresso em universidades são elevadas (91\% contra $62,6 \%$ para o resto de cidade). É fácil imaginar o quanto mais eles e outros poderiam conseguir no âmbito de uma lei federal que estimulasse e suportasse ativamente essa abordagem.

\section{Propostas alternativas para reformar a NCLB}

Mais de 150 grupos nacionais de educação, de direitos civis, de religiões, de deficientes, de civismo, de trabalhadores e outros assinaram até hoje a Joint Organizational Statement on NCLB (Declaração Conjunta de Organizações sobre a NCLB). Esta elenca os problemas da NCLB e recomenda reformas, inclusive um distanciamento da "confiança irrestrita em testes padronizados em favor de múltiplos indicadores do desempenho dos estudantes, além deles".

Dessa iniciativa surgiu o Forum on Educational Accountability (FEA - Fórum de Responsabilidade Educativa), que, em 2011, elaborou uma proposta para a revalidação da NCLB (FEA, 2011b). O plano garantiria que as escolas tivessem condições de ajudar todas as crianças a terem êxito e reservaria um papel razoável ao governo federal nas políticas educacionais, em vez de mandamentos de cima para baixo que costumam ser prescritivos demais e falhar em ajudar as escolas a alcançarem os objetivos educacionais e societais desejados. As propostas do FEA enfocam quatro pontos principais: rever as avaliações, reestruturar as responsabilidades, desenvolver a capacidade das escolas em atender bem todos os alunos, e tratar das necessidades humanas e sociais não atendidas, que são enfrentadas por muitas crianças. Cada uma está alicerçada em evidências sólidas - pesquisas e experiências práticas nos EUA e em outras nações.

Baseado em trabalhos realizados no estado de Massachusetts, o FairTest (2010b) tem promovido um programa de avaliação em três partes, que cada estado poderia implementar. O plano inclui coletar e avaliar provas da aprendizagem dos alunos todo ano e em cada escola a partir de dados oriundos das salas de aula e das escolas; aplicar testes padronizados de baixo impacto em leitura e matemática a todos os estudantes com intervalos de alguns anos, nos estados afora; e usar "revisões da qualidade das escolas" que envolvam times de peritos coordenando um estudo cuidadoso de cada escola a cada 4-6 anos, para verificar o quanto foi atendido do leque inteiro das necessidades dos alunos. Juntos, esses dados forneceriam um retrato muito mais rico da aprendizagem dos alunos e dos progressos da escola do que quaisquer testes padronizados. Ao mesmo tempo, evitariam as consequências nocivas da NCLB, como o ensino focado nas provas e o estreitamento do currículo.

Propostas de outros grupos, como a Broader, Bolder Agenda for Education (2008 - Agenda mais Ampla e Corajosa para a Educação), compartilham características 
fundamentais com as propostas de reforma do FairTest e do FEA, que as distinguem nitidamente da NCLB e dos seus derivados. Essas alternativas reconhecem explicitamente a necessidade de mudanças drásticas e fundamentais, em vez de incrementais, na lei. Afirmam que o objetivo da avaliação é ajudar os professores a melhorar a instrução e reforçar as escolas, não rotulá-los e puni-los. Defendem métodos para identificar os aprimoramentos mais precisamente necessários e melhor dirigir os esforços escolares e as ajudas externas. Declaram que as políticas públicas educacionais e outras devem atender as necessidades básicas, sociais, emocionais, de saúde e outras. Pedem uma educação integral para as crianças e a coleta de um leque de dados relevantes para tanto, inclusive oriundos de pesquisas sobre o ambiente escolar.

A NCLB foi promovida como um exemplo de consenso bipartidário sobre políticas educacionais. Com o tempo, ficou claro que os detalhes da lei, para não dizer alguns dos seus objetivos declarados, estavam fundamentalmente errados. Este relatório resumiu as provas do que deu errado, assim como o desafio atual das políticas educacionais da nação e como enfrentá-lo para melhorar a educação pública de modo significativo. Depois de uma década de estagnação, está na hora de usar essas provas para elaborar e votar uma nova lei educacional federal que ajude os nossos filhos, em vez de prejudicá-los.

\section{Notas}

1. O relatório do FairTest, Failing our children (Fracassando os nossos filhos - Neill, Guisbond \& Schaeffer, 2004), explicava o quanto os testes de alto impacto prejudicavam a qualidade da educação e solapavam as oportunidades individuais. De fato, explicava por que a NCLB acabaria deixando muitas crianças para trás.

2. N. do T.: Escolas financiadas com dinheiro público e administradas por um grupo privado de pessoas que promete uma melhoria significativa da qualidade educativa dentro de um período que vai de 3 a 5 anos. Podem ser vistas também como escolas administradas por concessão da gestão a grupos privados.

3. Isenções fazem parte da política educacional de Obama e visam dar "perdão" aos estados que acreditam que não vão conseguir cumprir os objetivos da NCLB previstos para 2014.

4. A RTTT oferecia bolsas de competitividade aos estados que concordassem em cumprir as políticas preferidas do governo, como a expansão das charter schools, as normas nacionais e as avaliações dos professores vinculadas aos resultados dos alunos nos testes.

\section{Referências}

ADVANCEMENT PROJECT et al. Federal Policy, esea reauthorization and the school to prison pipeline. March 2011 (revised). Disponível em: http://www.scribd.com/ doc/51122359/Advancement-Project-School-to-Prison-Pipeline-Position-Paper 
ASCHER, C. NCLB's supplemental educational services: is this what our students need? Phi Delta Kappan, Bloomington, v. 88, n. 2, p. 136-141, 2006.

AU, W. High-stakes testing and curricular control: a qualitative metasynthesis. Educational Researcher, Washington, DC, v. 36, n. 5, p. 258-267, 2007.

BERLINER, D. Poverty and potential: out of school factors and school success. Boulder: National Educational Policy Center, 2009. Disponível em: <http://nepc.colorado. edu/publication/poverty-and-potential>

BROADER, Bolder approach to Education. 2008. Disponível em:<http://www. boldapproach.org/index.php?id=51>

CAMPBELL, D.T. Assessing the impact of planned social change. Hanover: Dartmouth College, 1976.

COLEMAN, J. et al. Equality of educational opportunity. Washington, DC: Government Printing Office, 1966.

COMMON CORE. Learning less: public school teachers describe a narrowing curriculum; highlights from a survey by Common Core and the Farkas Duffett Research Group. 2011. Disponível em: <http://www.commoncore.org>

DARLING-HAMMOND, L. The flat world and education: how America's Commitment to Equity will determine our future. New York: Teachers College; Columbia University, 2010.

DUNCAN, G.; MURNANE, R. Whither opportunity?: rising inequality, schools and children's life chances. New York: Russell Sage, 2011.

DUNCAN, G.; MURNANE, R. Economic inequality: the real cause of the urban school problem. The Chicago Tribune, Chicago, Oct. 6, 2011. Disponível em: http:// articles.chicagotribune.com/2011-10-06/news/ct-perspec-1006-urban-20111006_1_ poor-children-graduation-rate-gap >

FAIRTEST. Naep results produce more evidence of NCLB's failure. 2009. Disponível em: $<$ http://www.fairtest.org/naep-results-produce-more-evidence-nclbs-failure>

FAIRTEST. Multiple measures: a definition and examples from the U.S. and other nations. 2010a. Disponível em: <http://www.fairtest.org/fact-sheet-multiple-measuresdefinition-and-examples>

FAIRTEST. A better way to evaluate schools. 2010b. Disponível em: <http://www.fairtest. org/fact-sheet-better-way-evaluate-schools-pdf>

FOLEY, B.; NEILL, M. Is AYP really dead?: a look at waivers and Esea reauthorization. 
2011. Disponível em: <http://fairtest.org/slide-show-basic-facts-about-duncans-aypwaiver-pl>

FORUM ON EDUCATIONAL ACCOUNTABILITY (FEA). All children deserve the opportunity to learn. FEA, 2011a. Disponível em: <http://www.edaccountability.org/ reports.html>

FORUM ON EDUCATIONAL ACCOUNTABILITY (FEA). FEA recommendations for improving Esea/NCLB. [S.1]: FEA, 2011b. Disponível em: <http://www.edaccountability. org/Legislative.html>

GEORGIA BUREAU OF INVESTIGATION (GBI). Special investigation into CRCT cheating at APS. [S.1.]: GBI, 2011a. Disponível em: <http://www.ajc.com/news/volume-1-ofspecial-1000798.html>

GEORGIA BUREAU OF INVESTIGATION (GBI). Dougherty County Investigative Report. [S.1.]: GBI, 2011b. 2v. Disponível em: <http://www.gaosa.org/>

GRUNDY, P.; SAWYER, C. The push behind a new flurry of testing. The News Observer, May 15, 2011. Disponível em: <http://www.newsobserver.com/2011/05/15/1196022/ the-push-behind-a-new-flurry-of.html>

HERALD WEEKLY (The). School district to collaborate with state on test development. 2011. Disponível em: <http://www.huntersvilleherald.com/education/2011/12/22/ school-district-to-collaborate-with-state-on-test-development/>

HOUT, M.; ELLIOTT, S. (Ed.). Incentives and test-based accountability in education: committee on incentives and test-based accountability in public education. Washington, DC: National Academies, 2011. Disponível em: <http://www.nap.edu/catalog. php?record_id=12521>

JOINT ORGANIZATIONAL STATEMENT ON NO CHILD LEFT BEHIND ACT. 2004. Disponível em: <http://www.edaccountability.org>

MASSACHUSETTS DEPARTMENT OF ELEMENTARY AND SECONDARY EDUCATION (DESE). Massachusetts Comprehensive Assessment System Schedule for MCAS and Mepa Testing. [S.1.]: Dese, 2011. Disponível em: <http://www.doe.mass. edu/mcas/cal.html>

MATHIS, W.J. NCLB's ultimate restructuring alternatives: do they improve the quality of education? Boulder and Tempe: Education and the Public Interest Research Center; Education Policy Research Unit, 2009. Disponível em: <http://nepc.colorado.edu/ publication/nclb-ultimate-restructuring>

MCMURRER, J. NCLB Year 5: choices, changes, and challenges: curriculum and 
instruction in the NCLB era. [S.1.]: Center on Education Policy, 2007. Disponível em: $<$ http://www.cep-dc.org/displayDocument.cfm?DocumentID=312>

MCNEIL, M. Majority of states say they'll seek waivers under NCLB. Education Week, 2011. Disponível em: <http://www.edweek.org/ew/articles/2011/10/13/08waivers.h31. html?r=953279945>

NATIONAL ASSOCIATION OF STATE BOARDS OF EDUCATION (NASBE). The complete curriculum: ensuring a place for the arts and foreign languages in America's schools; the report of the Nasbe study group on the lost curriculum. Alexandria: Nasbe, 2003.

NATIONAL CENTER FOR EDUCATION STATISTICS (NCES). Changes in instructional hours in four subjects by public school teachers of grades 1 through 4 (Issue Brief). [S.l.]:NCES, 2007. Disponível em: <http://nces.ed.gov/pubsearch/pubsinfo.asp?pubid=2007305>

NATIONAL CENTER FOR EDUCATION STATISTICS (NCES). The Nation's Report Card: long-term trend 2008. [S.1.]: NCES, 2008. Disponível em: <http://nces.ed.gov/ pubsearch/pubsinfo.asp?pubid=2009479>

NATIONAL CENTER FOR EDUCATIONAL STATISTICS (NCES). The Nation's Report Card: mathematics 2011. [S.1.]: NCES, 2011a. Disponível em: <http://nces.ed.gov/ nationsreportcard/>

NATIONAL CENTER FOR EDUCATIONAL STATISTICS (NCES). The nation's Report Card: reading 2011. [S.1.]: NCES, 2011b. Disponível em: <http://nces.ed.gov/ nationsreportcard/>

NEILL, M. Student test scores: an inaccurate way to judge teachers. 2011. Disponível em: <http://fairtest.org/sites/default/files/Student_Test_Scores_dangerous_way_to_ evaluate_teachers_-_4-24-11.pdf>

NEILL, M.; GUISBOND, L.; SCHAEFFER, R. Failing our children: how "No Child Left Behind" undermines quality and equity in education; an accountability model that supports school improvement. 2004. Disponível em: <http://fairtest.org/node/1778>

NEW YORK PERFORMANCE STANDARDS CONSORTIUM. New York, [s.d.]. Disponível em: <http://www.performanceassessment.org>

NEW YORK PRINCIPALS. An open letter of concern regarding New York State's APPR legislation for the evaluation of teachers and principals. 2011. Disponível em: <http:// www.newyorkprincipals.org/>

NICHOLS, S.; BERLINER, D. Collateral damage: how high-stakes testing corrupts America's schools. Cambridge, MA: Harvard Education, 2007. 
OFFICE OF PROFESSIONAL RESPONSIBILITY (OPR). Report of investigation. 2011. Disponível em: <http://www.scribd.com/doc/73055392/DISD-Field-Elementaryinvestigation>

PALLAS, A. The Nation's Report Card and NCLB: friends or foes? Boulder: National Education Policy Center, 2011. Disponível em: <http://nepc.colorado.edu/blog/nation\% E2\%80\%99s-report-card-and-nclb-friends-or-foes>

PERLSTEIN, L. Tested: one American school struggles to make the grade. New York: Henry Holt, 2007.

RAVITCH, D. What can we learn from Finland? Oct. 11, 2011a. Disponível em: <http:// blogs.edweek.org/edweek/Bridging-Differences/2011/10/what_can_we_learn_ from_finland.html>

RAVITCH, D. Do you believe in miracles? Dec. 6, 2011b. Disponível em: <http://blogs. edweek.org/edweek/BridgingDifferences/2011/12/do_you_believe_in_miracles. html>

ROTHSTEIN, R. Class and schools: using social, economic, and educational reform to close the black-white achievement gap. Washington, DC: Economic Policy Institute, 2004. Disponível em: <http://www.epi.org/publication/books_class_and_schools/>

ROTHSTEIN, R. Review of "Learning about teaching: initial findings from the measures of effective teaching project". Boulder: National Education Policy Center, 2011. Disponível em: <http://nepc.colorado.edu/thinktank/review-learning-about-teaching>

ROTHSTEIN, R. et al. Narrowing the achievement gap for low-incomechildren: a 19-year life cycle approach. Washington, DC: Economic Policy Institute, 2008. Disponível em: $<$ http://www.epi.org/publication/narrowing_the_achievement_gap_for_low-income_ children/>

SAWCHUK, S. What studies say about teacher effectiveness. Washington, DC: Education Writers Association, 2011. Disponível em: <http://www.ewa.org/site/PageServer? pagename=research_teacher_effectiveness $>$

U.S. CENSUS BUREAU, 2010. Income, poverty and health insurance coverage in the United States. 2011. Disponível em: <http://www.census.gov/newsroom/releases/archives/ income_wealth/cb11-157.html>

U.S. DEPARTMENT OF EDUCATION (DOE). The new consensus on middle-grades reform. 2011. (Remarks of U.S. Secretary of Education Arne Duncan to the Association for Middle Level Education (Amle) Annual Conference). Disponível em: <http:// www.ed.gov/news/speeches/new-consensus-middle-grades-reform> 
U.S. GOVERNMENT ACCOUNTABILITY OFFICE (GAO). Characteristics of tests will influence expenses: information sharing may help states realize efficiencies. Washington, DC: GAO, 2003. Disponível em: <www.gao.gov/new.items/d03389.pdf> U.S. GOVERNMENT ACCOUNTABILITY OFFICE (GAO). Education needs to provide additional technical assistance and conduct implementation studies for school choice provision. Washington, DC: GAO, 2004. Disponível em: <http://www.gao.gov/products/ GAO-05-7>

VON ZASTROW, C.; JANC, H. Academic atrophy: the condition of liberal arts in America's public schools. Washington, DC: Council for Basic Education, 2004. Disponível em: <http://www.ecs.org/html/Document.asp?chouseid=5058>

WAGNER, T. The Finland phenomenon: inside the world's most surprising school system. 2011. Disponível em: <http://www.2mminutes.com/products/pc/viewPrd. asp?idProduct $=22 \&$ idcategory $=24>$

WINERIP, M. In Tennessee, following the rules for evaluations off a cliff. The New York Times, New York, 2011. Disponível em: <http://www.nytimes.com/2011/11/07/education/ tennessees-rules-on-teacher-evaluations-bring-frustration.html?pagewanted=all>

ZELLMER, M. et al. What are NCLB's instructional costs? Educational Leadership, Washington DC, v. 64, n. 3, p. 43-46, 2006. Disponível em: http://www.ascd.org/publications/ educational-leadership/nov06/vol64/num03/What-Are-NCLB\%27s-InstructionalCosts\%C2\%A2.aspx > e <http://fairtest.org/NCLB-lost-decade-report-home $>$.

Recebido em 16 de janeiro de 2012.

Aprovado em 15 de fevereiro de 2012. 